Cite as: Rodriguez-Urrutia, A., Eiroa-Orosa, F. J., Accarino, A., Malagelada, C., \& Azpiroz, F. (2017). The role of incongruence between the perceived functioning by patients and clinicians in the detection of psychological distress among functional and motor digestive disorders. Journal of Psychosomatic Research, 99, 112-119. https://doi.org/10.1016/j.jpsychores.2017.06.005

\title{
The role of incongruence between the perceived functioning by patients and clinicians in the detection of psychological distress in functional and motor digestive disorders
}

\begin{abstract}
\section{Objectives}

Previous research on gastrointestinal and other medical conditions has shown the presence of incongruence between self- and clinician-reported functioning and its relation with psychopathology. The main objective of this study was to test whether inconsistencies between clinician- and self- assessed functionality can be used to detect psychopathology among patients diagnosed of motor or functional gastrointestinal disorders.
\end{abstract}

\section{Methods}

One hundred and three patients from a gastroenterology inpatient unit were included in this study. All patients underwent clinical assessment, including intestinal manometry, Rome III criteria for functional gastrointestinal disorders, and psychological and psychiatric evaluation. Patients with suspected gastroparesis underwent a gastric emptying test. Definitive diagnoses were made at discharge.

\section{Results}

Patients with higher levels of incongruence differed in various sociodemographic (age, educational level, work activity and having children) and psychopathological (all SCL-90-R subscales except anxiety and hostility) characteristics. Using general lineal models, incongruence was found to be the variable with stronger relations with psychopathology even when controlling for diagnosis. Interactions were found between incongruence and diagnosis reflecting a pattern in which patients with functional disorders whose subjective evaluation of functioning is not 
congruent with that of the clinician, have higher levels of psychopathology than patients with motor disorders.

\section{Conclusions}

Incongruence between clinician and self-reported functionality seems to be related to higher levels of psychopathology in patients with functional disorders. These findings underscore the need for routine psychosocial assessment among these patients. Gastroenterologists could use the concept of incongruence and its clinical implications, as a screening tool for psychopathology, facilitating consultation-liaison processes.

Keywords: incongruence, clinical performance, subjective functioning, psychological distress, functional gastrointestinal disorders, gastrointestinal motility disorders 


\section{Introduction}

People diagnosed of functional gastrointestinal disorders (FGDs) suffer from a wide range of medically unexplained symptoms involving visceral hypersensitivity and impaired gastrointestinal motility. These disorders have been widely related to psychosocial factors, such as patients' experiences of illness [1,2]. The integration of gut function with psychosocial assessment has been shown to help building an integrated clinical picture of these patients [3-5]. Psychosocial interventions such as psychotherapy, hypnotherapy or biofeedback are usually related to the effective improvement of functional digestive symptoms [6-8].

According to biopsychosocial models, multiple stressors can transiently or permanently alter physiologic stress responses producing symptoms and also differences in their perception, therefore perpetuating them. Nowadays, classic dualism separating mind and body seems to be surpassed by more integrative models [9]. Genetic predisposition and early-life stress might influence individual vulnerabilities to develop FGDs in adult life. Re-exposure to physiologic or psychological stressors may then trigger or exacerbate digestive symptoms [4]. Patients with FGDs usually report poor health-related quality of life [10-12], and that has been found to be related with psychopathology and functional comorbidities such as chronic fatigue syndrome, fibromyalgia or chronic pains [13]. Somatization, the tendency to experience and report multiple unexplained somatic symptoms, usually found among these patients [14], seems to play a key role in symptom severity and weight loss [15], and has been reported as the most important risk factor for impaired quality of life among patients diagnosed with functional dyspepsia [12]. Likewise, other psychopathological symptoms like anxiety and depression have been reported to worsen functional gastrointestinal symptoms [16]. 
Patient's experience with gastrointestinal motor disorders (GMDs) and its relation with distress have been less studied from the biopsychosocial perspective. Psychological distress seems to worsen the clinical picture among patients with gastroparesis [17]. Another study showed the presence of altered manometric observations in patients diagnosed with globus pharingeus [18]. In the psychiatric field, some studies have reported gastric dysmotility in patients diagnosed with schizophrenia [19] and depression [20,21]. Despite this evidence, no causal relationships or common ethiopathological mechanisms are well established.

One of the main problems faced by gastroenterological departments is the lack of resources and training for the screening and management of psychosocial factors related to FGDs. For instance, according to previous literature, gastroenterologists tend to misattribute FGDs diagnoses among patients with psychological distress [22]. Relatedly, our study group has shown in previous studies how the perception of functionality is different among clinicians and patients with FGDs, but congruent in patients with GMDs [23]. In a similar way, some studies in patients with asthma have shown incongruences between self-reported and clinician-reported measures [24]. Likewise in an analysis of the contrast between patient and physician assessments of medical comorbidities among patients diagnosed with chronic depression, the authors found that discrepancy was related to higher levels of depressive symptoms [25]. In a recent study we have found that psychopathology is related with incongruence between clinicians' and self-reported functionality assessments among patients diagnosed with gastrointestinal disorders [26].

The aim of this study is to verify the predictive capacity of the incongruity between the perceived functioning by patients and clinicians in the detection of psychological distress in functional and 
motor digestive disorders. Incongruence thus could be used as a tool of psychological distress screening for gastroenterologists facilitating mental health consultation-liaison processes.

\section{Methods}

Participants

We assessed for eligibility 119 patients with chronic and recurrent gastrointestinal symptoms without a clear diagnosis referred to our specialized digestive unit for diagnostic study. The protocol of the study had been approved by the local Ethics Committee and all participants gave their written informed consent.

\section{Assessment}

Psychiatric evaluation included a clinical interview conducted by a consultation liaison psychiatrist covering the main psychopathological domains according to DSM-IV TR [27] and additional administration of psychometric tests (see below). Digestive evaluation included intestinal manometry to evaluate small bowel motility and the administration of Rome III criteria, Karnofsky Performance Status scale and Body Mass Index in all patients. Patients with suspected gastroparesis underwent a scintigraphic gastric emptying test.

\section{Evaluation of small bowel motility by manometry}

Small bowel manometry was performed using a standard technique. After an overnight fast, a manometric tube (9012X1106 Special Manometric Catheter; Medtronic, Skovlunde, Denmark) was orally introduced into the jejunum under endoscopic guidance. Five manometric ports spanned at $10-\mathrm{cm}$ intervals were positioned from the proximal duodenum to the mid jejunum under fluoroscopic control. Stationary recording was performed for 3 hours during fasting and 2 
hours after ingestion of a solid-liquid meal $(450 \mathrm{kcal})$. Patients with recurrent episodes of acute intestinal pseudo-obstruction, were evaluated during a period of clinical remission. Manometric diagnosis of abnormal motility was established using the criteria routinely used in our unit that are based on previously published data [28].

\section{Scintigraphic gastric emptying test}

The gastric-emptying rate of the solid component of the meal was measured by an isotopic technique. The meal $(435 \mathrm{Kcal})$ consisted of a ham omelette $(50 \mathrm{~g}$ egg and $20 \mathrm{~g}$ sliced ham cooked with $5 \mathrm{~g}$ oil), toast ( $20 \mathrm{~g}$ white bread) with $5 \mathrm{~g}$ butter and $12 \mathrm{~g}$ marmalade, and $200 \mathrm{ml}$ fruit juice. The solid component of the meal was labelled by mixing $1 \mathrm{mCi} 99 \mathrm{mTc}$-sulfur colloid with the beaten egg before being cooked to a firm consistency. Abdominal scans in the postictal period were obtained with the subject standing in upright position in front of the gamma camera; anterior and posterior views were sequentially scanned by asking the subject to turn around in front of the camera. Corrections were performed by calculating the geometric mean of the sequential anterior and posterior counts. Corrections for isotope decay were also performed. In each scan the gastric outline was identified as region of interest and the activity of the isotope in the stomach was measured. The total activity of the isotope (100\%) was calculated in the first determination immediately after patients completed their meal by adding the activity detected within the gastric region to that already emptied from the stomach and detected outside the gastric region. Based on the proportion of meal residues remaining in the stomach at $4 \mathrm{~h}$, gastric emptying was graded as normal (> $10 \%$ retention) or delayed: mild (11-20\% retention), moderate (21-35\% retention) at $4 \mathrm{~h}$; severe, i.e., gastroparesis ( $<36-50 \%$ retention). 


\section{Diagnosis of functional gastrointestinal disorders}

All patients were further evaluated by means of structured interviews based on the Rome III criteria to determine the presence of criteria of functional gastrointestinal disorders [1].

\section{Clinician-rated functional impairment}

The Karnofsky Performance Status, KPS [29], was used to assess functional impairment caused by the digestive disease. This clinician-administered scale covers a range running from 0 (death) to 100 (perfect health).

\section{Psychosocial assessment}

The battery of self-administered questionnaires included:

- Subjective physical and social functionality was assessed by administering the Short Form Health Survey, SF-36 [30].

- The Symptom Checklist Revised, SCL-90-R [31] was used as a multidimensional measure of psychopathology (including somatization, obsessive-compulsive, interpersonal sensitivity, depression, anxiety, hostility, phobic anxiety, paranoid ideation and psychoticism).

Determination of incongruence between clinicians' assessment and patients' self-reported functionality

Within the patients among which it was possible to collect both the value of the Karnofsky performance scale and the SF-36 questionnaire, we defined incongruence as a value above 25 on the difference of the former with the physical functioning subscale of the latter. The reasoning behind this determination was to detect patients with lower levels of performance that could be 
explained by the digestive disease. Based on this cut-off, two groups were defined: patients among whom there was congruence between their perceived and clinician-assessed functionality, and patients among whom the scores were not congruent. As we can see in Figure 1, these values allowed us to divide the group of patients among those in which the relationship between self and hetero-reported functionality was almost perfect and those in which it was nil keeping a balance of similar proportions in both diagnostic groups. According to this cut-off the proportion of patients with incongruence was near $40 \%$ in both groups (FGD: 39.7\%, GMD: 40\%, OR=.989, 95\% CI=.394-2.482, $\mathrm{p}=.982)$.

Figure 1. Scatter plot showing the relative congruence between clinician- and self-assessed functioning.

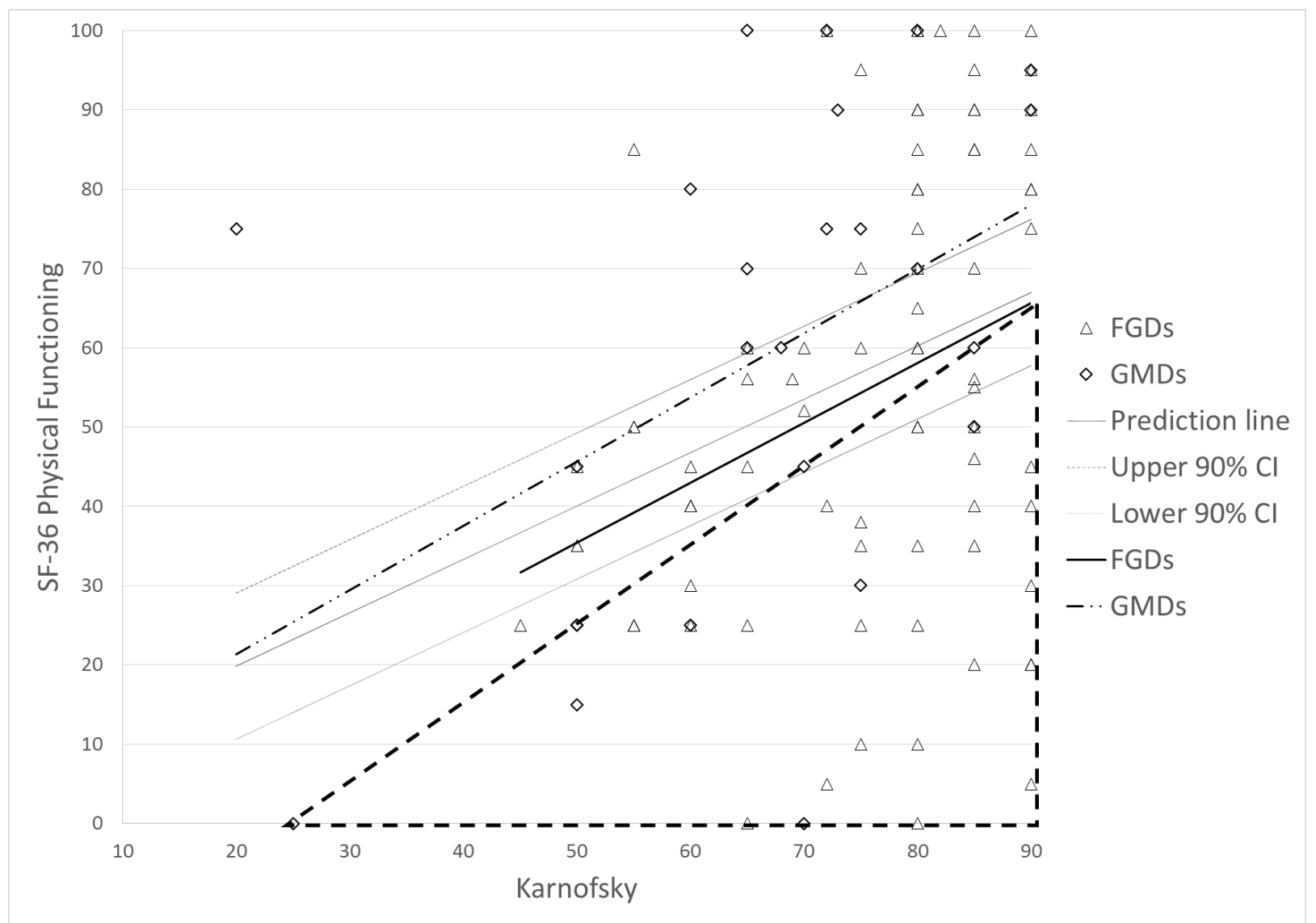




\section{Data analysis}

T-tests were used to compare continuous socio-demographic characteristics and psychopathology measures between congruence groups. Categorical variables were compared between groups using chi-squared tests for independence. Finally, general linear models were used to calculate the interaction of incongruence and diagnosis in the 9 SCL-90-R psychopathology dimensions. Given the high number of variables we applied Bonferroni corrections for multiple comparisons.

\section{Results}

One hundred nineteen patients were enrolled in the study. Eight patients were excluded from the study after the psychiatric and digestive assessment as they did not meet criteria for a FGD or a GMD, and eight were not able to fill psychometric test and were also excluded.

\section{Results of the Gastrointestinal evaluation}

From the final one hundred and three patients included, twenty-five patients fulfilled criteria of intestinal dysmotility and 78 did not. Patients with diagnosis of intestinal dysmotility presented either a) relapsing acute episodes of intestinal pseudo-obstruction $(n=18)$ with radiological evidence of intestinal air fluid levels interspersed with relatively symptom-free intervals, or b) symptoms compatible with gastroparesis, i.e. chronic (>6 months) postprandial symptoms, such as nausea, vomiting, poorly satiation, postprandial fullness, abdominal discomfort/pain, and distension $(n=7)$, with reduced feeding tolerance and inability to maintain normal body weight, i.e. Body Mass Index (BMI) below 18.7 in women and 20.1 in men. 
Figure 2. Flow diagram of the study

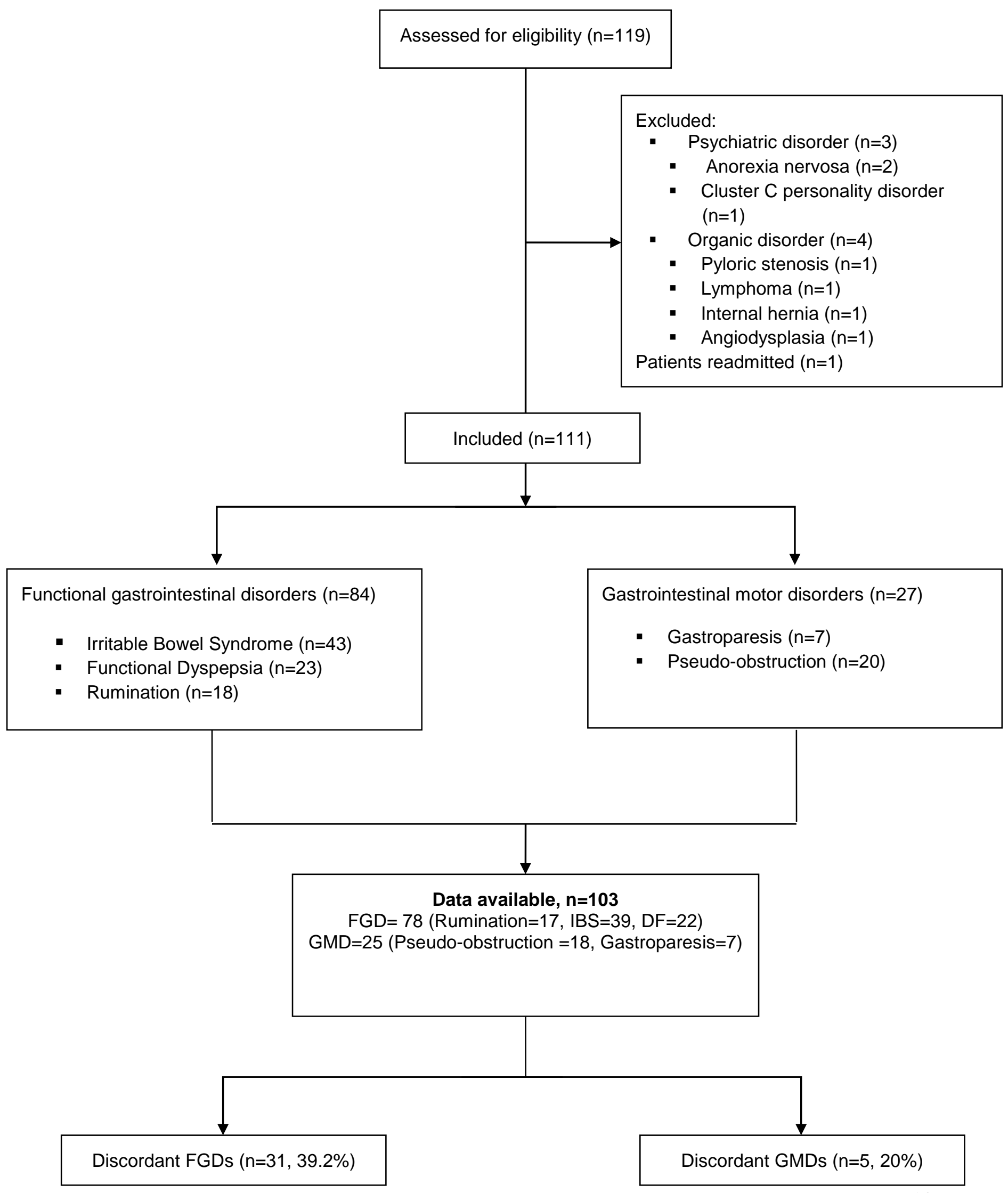


Among the 78 patients not fulfilling criteria of intestinal dysmotility, 29 presented clinical features compatible with gastroparesis; in all of them gastroparesis was ruled out by evaluation of gastric motor function. These patients presented early satiation, postprandial fullness, epigastric discomfort/pain and all fulfilled Rome III criteria for functional dyspepsia. In 22 of them gastric abnormalities of functional dyspepsia were found. The 56 remaining patients without objective evidence of gastrointestinal motor disorder (intestinal dysmotility or gastroparesis) 39 presented recurrent abdominal pain or discomfort with constipation, diarrhea or both, all fulfilled Rome III criteria of Irritable Bowel Syndrome (IBS), and 17 presented persistent or recurrent regurgitation of recently ingested food into the mouth that fulfilled Rome III criteria of Rumination Syndrome.

\section{Sociodemographic and psychosocial characteristics}

Sociodemographic characteristics by congruence groups are shown in table 1. Patients among whom it was judged that there was a congruence between their perceived and clinician-assessed functionality were statistically significantly younger, had higher levels of education, were more likely to be professionally active, and less likely to have children Having children and professional activity remained statistically active after Bonferroni adjustment $(.05 / 8=.006)$. No statistically significant differences were found in gender distribution, marital status and just a tendency was found for higher proportion of psychiatry history among patients with incongruence. 
Table 1. Sociodemographic and psychosocial characteristics of the sample by incongruence

\begin{tabular}{|c|c|c|c|c|c|c|}
\hline \multirow{4}{*}{ Age $(\mathrm{M} \pm \mathrm{SD})$} & \multicolumn{2}{|c|}{ Incongruence $(n=41)$} & \multicolumn{2}{|c|}{ No incongruence $(n=62)$} & \multicolumn{2}{|l|}{ Significance } \\
\hline & $\mathrm{M}$ & SD & $\mathrm{M}$ & $\mathrm{SD}$ & $\mathrm{t}$ & $\mathrm{p}$ \\
\hline & 44.24 & 11.42 & 38.63 & 14.60 & 2.076 & .040 \\
\hline & $\mathrm{N}$ & $\%$ & $\mathrm{~N}$ & $\%$ & OR, $95 \% \mathrm{CI}$ & $\mathrm{p}$ \\
\hline Sex (\% females) & 35 & 85.4 & 47 & 75.8 & $1.862, .656-5.823$ & .238 \\
\hline Education (at least higher or vocational) & 11 & 26.8 & 29 & 46.8 & $2.397,1.022-5.619$ & .042 \\
\hline Professionally active* & 22 & 53.7 & 50 & 80.6 & $3.598,1.493-8.672$ & .003 \\
\hline $\begin{array}{l}\text { Marital status (married or stable couple) } \\
* *\end{array}$ & 28 & 68.3 & 35 & 56.7 & $.602,263-1.377$ & .227 \\
\hline Children (yes) & 32 & 78.0 & 29 & 46.8 & $4.046,1.658-9.873$ & .002 \\
\hline Psychiatric history (yes) & 25 & 61.0 & 26 & 41.9 & $2.163, .967-4.840$ & .059 \\
\hline
\end{tabular}

FGD: functional gastrointestinal disorders (functional dyspepsia, rumination and irritable bowel syndrome).

GMD: gastrointestinal motility disorders (chronic intestinal pseudo-obstruction, gastroparesis and inability).

These categories were collapsed because of low $n$ :

*Any work activity or studies

**The rest includes: single, divorced, and widow patients 


\section{Psychopathology}

Differences in psychopathology variables by diagnostic and incongruence groups are shown in figure 3. When comparing scores between diagnostic groups, no SCL-90-R subscale showed statistically significant differences. In the case of incongruence, all subscales except anxiety $(\mathrm{t}=1.850, \mathrm{p}=.067)$ and hostility $(\mathrm{t}=1.482, \mathrm{p}=.141)$ showed statistically significant differences, with higher values for patients with incongruent scores. After applying Bonferroni corrections for multiple comparisons $(.05 / 9=.0055)$ only phobic anxiety lost statistical significance. Within diagnostic groups, no statistically significant difference was found between GMD incongruence patients groups, while all the SCL-90-R scores were found to be statistically different between FGD incongruence patient groups.

Table 2 shows the results of the general linear models using diagnosis and congruence as factors (independent variables) and psychopathology dimensions as dependent variables. No variable showed between subjects' effects regarding diagnosis and incongruence retained statistical significance just in the case of somatization and depression. Interaction between both variables was statistically significant in the case of interpersonal sensitivity, phobic anxiety, psychoticism and the overall generalized form (MANOVA). 
Table 2. General linear models of SCL-90 scores

\begin{tabular}{|c|c|c|c|c|c|c|c|c|c|}
\hline \multirow[t]{2}{*}{$\begin{array}{l}\text { Independent } \\
\text { variable }\end{array}$} & \multirow{2}{*}{$\begin{array}{c}\text { Incongruence } \\
\mathrm{F} \\
\end{array}$} & \multirow{2}{*}{$\begin{array}{l}\text { Diagnosis } \\
\text { (FGD. } \\
\text { GMD) } \\
p\end{array}$} & & & & teracti & & & \\
\hline & & & $\eta p^{2}$ & $\mathrm{~F}$ & $\mathrm{p}$ & $\eta p^{2}$ & $\mathrm{~F}$ & $\mathrm{p}$ & $\eta p^{2}$ \\
\hline Somatisation & 8.274 & .005 & .078 & .582 & .447 & .006 & .114 & .736 & .001 \\
\hline $\begin{array}{l}\text { Obsessive- } \\
\text { compulsive }\end{array}$ & 3.685 & .058 & .036 & .025 & .874 & .000 & 1.135 & .289 & .011 \\
\hline $\begin{array}{l}\text { Interpersonal } \\
\text { sensitivity }\end{array}$ & 1.531 & .219 & .015 & .184 & .669 & .002 & 7.642 & .007 & .072 \\
\hline Anxiety & 1.484 & .226 & .015 & .047 & .828 & .000 & .498 & .482 & .005 \\
\hline Depression & 4.736 & .032 & .046 & .324 & .571 & .003 & 1.546 & .217 & .016 \\
\hline Hostility & .617 & .434 & .006 & .077 & .782 & .001 & .890 & .348 & .009 \\
\hline Phobic anxiety & .758 & .386 & .008 & 2.591 & .111 & .026 & 8.216 & .005 & .077 \\
\hline Psychoticism & 2.270 & .135 & .023 & .099 & .753 & .001 & 4.184 & .043 & .041 \\
\hline Paranoid ideation & 2.477 & .119 & .025 & .256 & .614 & .003 & 3.206 & .076 & .032 \\
\hline $\begin{array}{l}\text { MANOVA } \\
\text { (Phillai's trace) }\end{array}$ & 1.509 & .157 & .131 & 1.178 & .319 & .105 & 2.035 & .044 & .169 \\
\hline
\end{tabular}


Figure 3. SCL-90 mean scores by diagnosis and congruence groups

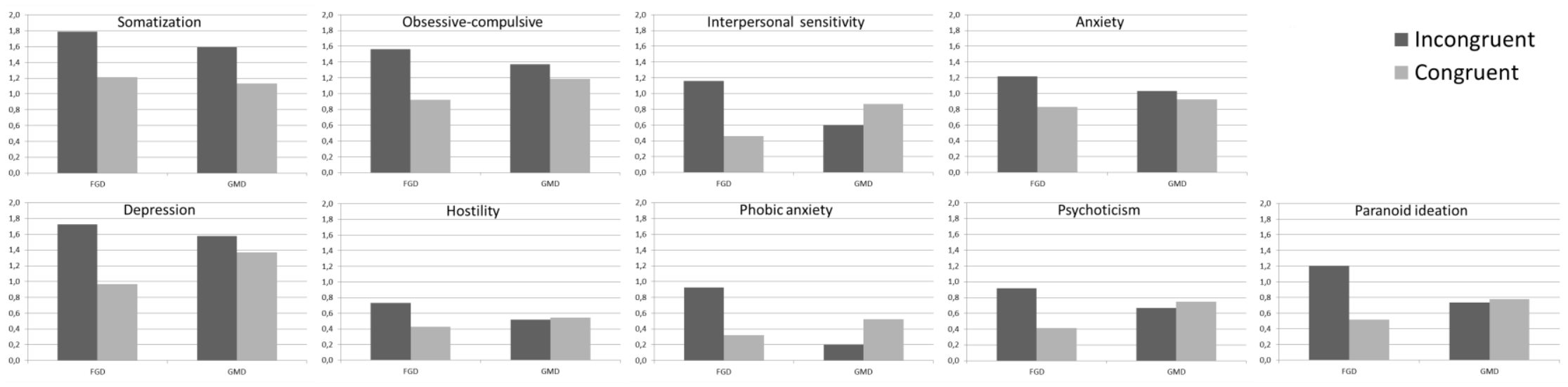




\section{Discussion}

Our study shows how the incongruence between clinician-assessed and patient self-reported functionality could be a straightforward tool for the screening of psychological distress at gastroenterology units.

Patients with incongruence were older, were more likely to be professionally inactive, to have lower levels of education and were more likely to have children. Patients whose views of functionality were incongruent with those of the clinicians were nearly six years on average older than those who did not. The presence of incongruence may hinder the integrated understanding of the whole clinical picture by gastroenterologists lengthening the diagnosis process and hampering the implementation of an adequate treatment. The age of patients might be also be related to the likelihood of having children. Furthermore, the more complicated clinical picture of patients with views of their functioning incongruent with those of the clinician, might be related with lower social functioning capacities.

In our study, incongruence is related with absolute differences in all psychopathological domains although statistical significance and control for multiple comparisons excluded anxiety, hostility and phobic anxiety. In turn, we did not obtain any statistical significance when comparing psychopathology dimensions between diagnosis groups. Somatization and depression showed between subjects' statistically significant effects for incongruence when also controlling for diagnosis. These two variables are those with a greater difference between congruence patient groups when even controlling for diagnosis. Interactions between incongruence and diagnosis were found for interpersonal sensitivity, phobic anxiety and psychoticism. In these three cases GMD patients with congruent assessments showed slightly higher (but not statistically significant 
when compared using t-tests) levels of psychopathology than their peers. In contrast, the situation among FGDs showed a dramatic predominance of psychopathology among patients with incongruence when compared with their congruent peers.

Somatization has been widely found among patients diagnosed with IBS [32] as it seems to increase postprandial symptoms among them [33]. On the one hand, the relationship between higher levels of psychopathology and the incongruence of clinicians and patient's perception in FGDs, could be related to somatosensory amplification [1,2,34], a psychobiological mechanism which amplifies body symptoms perception and that it is maybe not well taken into account by gastroenterologists [35]. In our study, somatization measured by the SCL-90-R does not allow us to deepen in the origin of somatization. Some previous studies have shown how somatosensory amplification is related to FGDs $[34,36]$ and it has been found to be related with increased report of drugs' side effects [37]. On the other hand, as we showed in an earlier publication [26] increased levels of somatization as measured with the SCL-90-R among patients with GMDs, could be explained by severe medical conditions. Among these patients, incongruence could be related to the way that patients with severe medical comorbidities express their discomfort. Our finding related to the higher levels of depressive symptomatology among congruent patients agrees with the results found by Schrader [25]. Depressive symptoms have classically been related to negative perceptions and distortions [38]. In this regard depressive symptomatology might be related to uncontrollability and unpredictability cognitions that have been related with decreased levels of physical health [39].

Obsessive-compulsive symptoms were also strongly related to incongruence just in patients with FGDs. One possible explanation is that patients with obsessive symptoms have higher levels of 
psychological inflexibility. Psychological flexibility has been defined as a present-mindedness approach to situation-response, accepting and adapting own behaviors based on personally held values [40]. In contrast, psychological inflexibility is marked by disabling avoidance and ruminative thoughts, which interfere with personal self-direction [41]. Previous research has evidenced how psychological factors such as inflexibility, hypervigilance, attentional bias and pain catastrophizing increase abdominal pain sensations and worsen the prognosis of these patients [42]. Obsessive-compulsive symptoms may increase the digestive pain experience via psychological mechanisms as hypervigilance, causing the incongruence between clinicianassessed and subjective measures [43]. Further research showed how IBS was highly present $(35,1 \%)$ in a sample of patients diagnosed with obsessive-compulsive disorder (OCD) [44]. Authors attribute this relation to the neurobiological common pathways via 5-HT receptors in both diseases and in other FGDs. In addition, some brain treatments for resistant OCD seem to improve IBS symptoms [45]. Some studies in fMRI show how the anterior cingulate cortex (ACC) is significantly more active in patients with OCD. It is known that the ACC is involved in visceromotor control and nociception [46].

All these results taken together highlight the importance of taking into consideration the differences that occur when it is self-reported or clinician-rated [47]. Relatedly, subjective health assessment by patients might give gastroenterologists additional information about their overall clinical picture [48]. Incongruences between clinician's and patients perceptions of quality of life have been found in medical conditions such as multiple sclerosis [49], asthma [24], or hip arthroplasty [50], and seems to be related with different clinical outcomes such as macular degeneration [51,52]. A previous study showed how incongruence was related to depression [25], as it happens in our study, especially among patients diagnosed with FGDs. For that reason we 
uphold that incongruence can be a simple screening tool for gastroenterological use aiming to detect patients who need further mental health support. In this sense, previous literature shows evidence for the use of psychological $[7,53,54]$ and psychotropic drugs $[55,56]$.

Limitations of our study should also be discussed. On the one hand, our study was carried in a highly-specialized tertiary gastrointestinal unit. Further studies should be carried to be able to settle whether incongruence is related to psychopathology in patients with FGDs treated at different healthcare levels. On the other hand, we haven't used specific assessment tools for each digestive diagnostic included in this study. However, we used universal psychometric tests that allowed us to compare psychological distress in different diagnostic groups. In addition, crosssectional evaluation doesn't allow us to deepen in the causes of clinical incongruence, preventing us to delve into the reasons for the higher age and the possible differences in the evolution of the disorder. These limitations may hamper the generalizability of our results to other clinical settings such as primary or secondary care.

In spite of the evidence of increased psychological distress, psychosocial assessment seems to be a gap in the diagnostic process of digestive patients. Furthermore, digestive patients might suffer from subclinical psychiatric syndromes, not easily diagnosable by common clinical interviews [2]. Some authors have tried to improve this situation designing diagnostic tools able to detect subsyndromal symptoms, psychosomatic reactions [57,58] and specific psychopathology symptoms [59] in digestive patients, although its use is still not generalized in this population.

In this study we have seen how psychopathology seems to be related to the different perceptions of illness that clinicians and patients have. Therefore, incongruence of patient and clinician- 
provided functionality can be used as a simple screening tool for psychopathology, especially among patients with FGDs, facilitating the mental health consultation-liaison processes.

\section{References}

[1] D.A. Drossman, F.H. Creed, K.W. Olden, J. Svedlund, B.B. Toner, W.E. Whitehead, Psychosocial aspects of the functional gastrointestinal disorders., Gut. 45 Suppl 2 (1999) II25-30.

[2] P. Porcelli, O. Todarello, Psychological factors affecting functional gastrointestinal disorders., Adv. Psychosom. Med. 28 (2007) 34-56. doi:10.1159/0000106796.

[3] D.G. Folks, The interface of psychiatry and irritable bowel syndrome, Curr. Psychiatry Rep. 6 (2004) 210-215. doi:10.1007/s11920-004-0066-0.

[4] M.P. Jones, M.D. Crowell, K.W. Olden, F. Creed, Functional gastrointestinal disorders: an update for the psychiatrist., Psychosomatics. $48 \quad$ (2007) 93-102. doi:10.1176/appi.psy.48.2.93.

[5] R. Sood, D.J. Gracie, G.R. Law, a. C. Ford, Systematic review with meta-analysis: the accuracy of diagnosing irritable bowel syndrome with symptoms, biomarkers and/or psychological markers, Aliment. Pharmacol. Ther. 42 (2015) 491-503. doi:10.1111/apt.13283.

[6] E. Barba, E. Burri, A. Accarino, C. Malagelada, A. Rodriguez-Urrutia, A. Soldevilla, J.-R. Malagelada, F. Azpiroz, Biofeedback-Guided Control of Abdominothoracic Muscular Activity Reduces Regurgitation Episodes in Patients With Rumination, Clin. Gastroenterol. Hepatol. 13 (2015) 100-106.e1. doi:10.1016/j.cgh.2014.04.018.

[7] V. Miller, H.R. Carruthers, J. Morris, S.S. Hasan, S. Archbold, P.J. Whorwell, Hypnotherapy for irritable bowel syndrome: an audit of one thousand adult patients., 
Aliment. Pharmacol. Ther. 41 (2015) 844-55. doi:10.1111/apt.13145.

[8] M.B.O. Lowén, E.A. Mayer, M. Sjöberg, K. Tillisch, B. Naliboff, J. Labus, P. Lundberg, M. Ström, M. Engström, S.A. Walter, Effect of hypnotherapy and educational intervention on brain response to visceral stimulus in the irritable bowel syndrome., Aliment. Pharmacol. Ther. 37 (2013) 1184-97. doi:10.1111/apt.12319.

[9] E.A. Mayer, K. Tillisch, The Brain-Gut Axis in Abdominal Pain Syndromes, Annu. Rev. Med. 62 (2011) 381-396. doi:10.1146/annurev-med-012309-103958.

[10] L. Chang, Review article: epidemiology and quality of life in functional gastrointestinal disorders., Aliment. Pharmacol. Ther. 20 Suppl 7 (2004) 31-9. doi:10.1111/j.13652036.2004.02183.x.

[11] N.J. Talley, Functional dyspepsia, delayed gastric emptying, and impaired quality of life, Gut. 55 (2006) 933-939. doi:10.1136/gut.2005.078634.

[12] L. Van Oudenhove, J. Vandenberghe, R. Vos, L. Holvoet, K. Demyttenaere, J. Tack, Risk factors for impaired health-related quality of life in functional dyspepsia, Aliment. Pharmacol. Ther. 33 (2011) 261-274. doi:10.1111/j.1365-2036.2010.04510.x.

[13] J. Vu, V. Kushnir, B. Cassell, C.P. Gyawali, G.S. Sayuk, The impact of psychiatric and extraintestinal comorbidity on quality of life and bowel symptom burden in functional GI disorders, Neurogastroenterol. Motil. 26 (2014) 1323-32. doi:10.1111/nmo.12396.

[14] N. Clauwaert, M.P. Jones, L. Holvoet, J. Vandenberghe, R. Vos, J. Tack, L. Van Oudenhove, Associations between gastric sensorimotor function, depression, somatization, and symptom-based subgroups in functional gastroduodenal disorders: are all symptoms equal?, Neurogastroenterol. Motil. (2012). doi:10.1111/j.1365-2982.2012.01985.x.

[15] L. Van Oudenhove, J. Vandenberghe, B. Geeraerts, R. Vos, P. Persoons, B. Fischler, K. Demyttenaere, J. Tack, Determinants of symptoms in functional dyspepsia: gastric 
sensorimotor function, psychosocial factors or somatisation?, Gut. 57 (2008) 1666-73. doi:10.1136/gut.2008.158162.

[16] J.M. Lackner, C.-X. Ma, L. Keefer, D.M. Brenner, G.D. Gudleski, N. Satchidanand, R. Firth, M.D. Sitrin, L. Katz, S.S. Krasner, S.K. Ballou, B.D. Naliboff, E.A. Mayer, Type, Rather Than Number, of Mental and Physical Comorbidities Increases the Severity of Symptoms in Patients With Irritable Bowel Syndrome, Clin. Gastroenterol. Hepatol. 11 (2013) 1147-1157. doi:10.1016/j.cgh.2013.03.011.

[17] W.L. Hasler, H.P. Parkman, L.A. Wilson, P.J. Pasricha, K.L. Koch, T.L. Abell, W.J. Snape, G. Farrugia, L. Lee, J. Tonascia, A. Unalp-Arida, F. Hamilton, Psychological dysfunction is associated with symptom severity but not disease etiology or degree of gastric retention in patients with gastroparesis., Am. J. Gastroenterol. 105 (2010) 2357-67. doi:10.1038/ajg.2010.253.

[18] M.A. Kwiatek, F. Mirza, P.J. Kahrilas, J.E. Pandolfino, Hyperdynamic upper esophageal sphincter pressure: a manometric observation in patients reporting globus sensation., Am. J. Gastroenterol. 104 (2009) 289-98. doi:10.1038/ajg.2008.150.

[19] J. Peupelmann, C. Quick, S. Berger, M. Hocke, M.E. Tancer, V.K. Yeragani, K.-J. Bär, Lidicate gastric dysmotility in patients sunear and non-linear measures inffering from acute schizophrenia., Prog. Neuropsychopharmacol. Biol. Psychiatry. 33 (2009) 1236-40. doi:10.1016/j.pnpbp.2009.07.007.

[20] C. Quick, A. Kliem, S. Berger, M. Hocke, M. Tancer, G. Juckel, V.K. Yeragani, K.-J. Bär, Gastric dysmotility in major depression., Prog. Neuropsychopharmacol. Biol. Psychiatry. 34 (2010) 92-7. doi:10.1016/j.pnpbp.2009.10.003.

[21] C. Ruhland, M. Koschke, W. Greiner, J. Peupelmann, U. Pietsch, M. Hocke, V.K. Yeragani, K.-J. Bär, Gastric dysmotility in patients with major depression., J. Affect. 
Disord. 110 (2008) 185-90. doi:10.1016/j.jad.2007.12.236.

[22] L. Keefer, G. Sayuk, J. Bratten, R. Rahimi, M.P. Jones, Multicenter Study of Gastroenterologists' Ability to Identify Anxiety and Depression in a New Patient Encounter and its Impact on Diagnosis, J. Clin. Gastroenterol. 42 (2008) 667-671. doi:10.1097/MCG.0b013e31815e84ff.

[23] F.J. Eiroa-Orosa, A. Rodriguez-Urrutia, A. Accarino, P. Santamarina-Perez, G. Parramon, F. Azpiroz, An exploratory study comparing psychological profiles and its congruence with clinical performance among patients with functional or motility digestive disorders, J. Health Psychol. 21 (2016) 2590-2599. doi:10.1177/1359105315581069.

[24] M.K. Cowen, D.B. Wakefield, M.M. Cloutier, Classifying asthma severity: objective versus subjective measures., J. Asthma. 44 (2007) 711-5. doi:10.1080/02770900701595576.

[25] G.D. Schrader, Subjective and Objective Assessments of Medical Comorbidity in Chronic Depression, Psychother. Psychosom. 66 (1997) 258-260. doi:10.1159/000289144.

[26] A. Rodriguez-Urrutia, F.J. Eiroa-Orosa, A. Accarino, C. Malagelada, F. Azpiroz, Incongruence between Clinicians' Assessment and Self-Reported Functioning Is Related to Psychopathology among Patients Diagnosed with Gastrointestinal Disorders, Psychother. Psychosom. 85 (2016) 244-245. doi:10.1159/000443899.

[27] American Psychiatric Association, ed., Diagnostic and statistical manual of mental disorders: DSM-IV-TR., American Psychiatric Publishing, 2000.

[28] J. Serra, A. Villoria, F. Azpiroz, B. Lobo, J. Santos, A. Accarino, J.R. Malagelada, Impaired intestinal gas propulsion in manometrically proven dysmotility and in irritable bowel syndrome, Neurogastroenterol. Motil. 22 (2010) 401-e92. doi:10.1111/j.13652982.2009.01447.x. 
[29] D. Karnofsky, J. Burchenal, The Clinical Evaluation of Chemotherapeutic Agents in Cancer, in: C. MacLeod (Ed.), Eval. Chemother. Agents, Columbia Univ Press, 1949: p. 196.

[30] J.E. Ware, C.D. Sherbourne, The MOS 36-item short-form health survey (SF-36). I. Conceptual framework and item selection., Med. Care. 30 (1992) 473-83.

[31] L.R. Derogatis, SCL-90-R: Administration, scoring and procedures manual (3rd edition), Baltimore, 1994.

[32] P. Patel, P. Bercik, D.G. Morgan, C. Bolino, M.I. Pintos-Sanchez, P. Moayyedi, A.C. Ford, Irritable bowel syndrome is significantly associated with somatisation in 840 patients, which may drive bloating., Aliment. Pharmacol. Ther. 41 (2015) 449-58. doi:10.1111/apt.13074.

[33] L. Van Oudenhove, H. Törnblom, S. Störsrud, J. Tack, M. Simrén, Depression and Somatization are Associated with Increased Postprandial Symptoms in Patients With Irritable Bowel Syndrome., Gastroenterology. (2015). doi:10.1053/j.gastro.2015.11.010.

[34] M.P. Jones, A. Schettler, K. Olden, M.D. Crowell, Alexithymia and somatosensory amplification in functional dyspepsia., Psychosomatics. 45 (2004) 508-516. doi:10.1176/appi.psy.45.6.508.

[35] M.I. Pinto-Sanchez, A.C. Ford, C.A. Avila, E.F. Verdu, S.M. Collins, D. Morgan, P. Moayyedi, P. Bercik, Anxiety and Depression Increase in a Stepwise Manner in Parallel With Multiple FGIDs and Symptom Severity and Frequency, Am. J. Gastroenterol. 110 (2015) 1038-1048. doi:10.1038/ajg.2015.128.

[36] M.P. Jones, L.M. Roth, M.D. Crowell, Symptom reporting by functional dyspeptics during the water load test., Am. J. Gastroenterol. 100 (2005) 1334-9. doi:10.1111/j.15720241.2005.40802.x. 
[37] B.K. Doering, Y. Nestoriuc, A.J. Barsky, H. Glaesmer, E. Brähler, W. Rief, Is somatosensory amplification a risk factor for an increased report of side effects? Reference data from the German general population, J. Psychosom. Res. 79 (2015) 492-497. doi:10.1016/j.jpsychores.2015.10.010.

[38] R.E. Nelson, W.E. Craighead, Selective recall of positive and negative feedback, selfcontrol behaviors, and depression., J. Abnorm. Psychol. 86 (1977) 379-388. doi:10.1037/0021-843X.86.4.379.

[39] A.W. Evers, F.W. Kraaimaat, W. van Lankveld, P.J. Jongen, J.W. Jacobs, J.W. Bijlsma, Beyond unfavorable thinking: the illness cognition questionnaire for chronic diseases., J. Consult. Clin. Psychol. 69 (2001) 1026-36. doi:10.1037/0022-006X.69.6.1026.

[40] S.C. Hayes, J.B. Luoma, F.W. Bond, A. Masuda, J. Lillis, Acceptance and commitment therapy: model, processes and outcomes., Behav. Res. Ther. 44 (2006) 1-25.

[41] M.M. Lilly, C.E. Allen, Psychological Inflexibility and Psychopathology in 9-1-1 Telecommunicators., J. Trauma. Stress. (2015).

[42] L. Keefer, S. Mandal, The potential role of behavioral therapies in the management of centrally mediated abdominal pain, Neurogastroenterol. Motil. 27 (2015) 313-323. doi:10.1111/nmo.12474.

[43] I. Posserud, J. Svedlund, J. Wallin, M. Simrén, Hypervigilance in irritable bowel syndrome compared with organic gastrointestinal disease, J. Psychosom. Res. 66 (2009) 399-405. doi:10.1016/j.jpsychores.2008.09.020.

[44] P.S. Masand, N.J. Keuthen, S. Gupta, S. Virk, B. Yu-Siao, D. Kaplan, Prevalence of irritable bowel syndrome in obsessive-compulsive disorder., CNS Spectr. 11 (2006) 21-5.

[45] B. Langguth, K. Sturm, T.C. Wetter, M. Lange, L. Gabriels, E. a. Mayer, J. Schlaier, Deep Brain Stimulation for Obsessive Compulsive Disorder Reduces Symptoms of Irritable 
Bowel Syndrome in a Single Patient, Clin. Gastroenterol. Hepatol. (2015). doi:10.1016/j.cgh.2015.01.023.

[46] B. Bonaz, Visceral sensitivity perturbation integration in the brain-gut axis in functional digestive disorders., J. Physiol. Pharmacol. 54 Suppl 4 (2003) 27-42.

[47] M. Manning, J. Burnett, R. Chapman, Predicting Incongruence between Self-reported and Documented Colorectal Cancer Screening in a Sample of African American Medicare Recipients, Behav. Med. (2015) 1-10. doi:10.1080/08964289.2015.1011600.

[48] A.L. Krarup, E. Peterson, G. Ringström, H. Törnblom, H. Hjortswang, M. Simrén, The Short Health Scale: A Simple, Valid, Reliable, and Responsive Way of Measuring Subjective Health in Patients With Irritable Bowel Syndrome., J. Clin. Gastroenterol. (2014). doi:10.1097/MCG.0000000000000209.

[49] P.M. Rothwell, Z. McDowell, C.K. Wong, P.J. Dorman, Doctors and patients don't agree: cross sectional study of patients' and doctors' perceptions and assessments of disability in multiple sclerosis, BMJ. 314 (1997) 1580-1580. doi:10.1136/bmj.314.7094.1580.

[50] J.R. Lieberman, F. Dorey, P. Shekelle, L. Schumacher, B.J. Thomas, D.J. Kilgus, G.A. Finerman, Differences between patients' and physicians' evaluations of outcome after total hip arthroplasty., J. Bone Joint Surg. Am. 78 (1996) 835-8.

[51] J.D. Stein, M.M. Brown, G.C. Brown, H. Hollands, S. Sharma, Quality of life with macular degeneration: perceptions of patients, clinicians, and community members., Br. J. Ophthalmol. 87 (2003) 8-12. doi:10.1136/bjo.87.1.8.

[52] G.C. Brown, M.M. Brown, S. Sharma, Difference between ophthalmologists' and patients' perceptions of quality of life associated with age-related macular degeneration., Can. J. Ophthalmol. 35 (2000) 127-33. doi:10.1016/S0008-4182(00)80005-8.

[53] L. Li, L. Xiong, S. Zhang, Q. Yu, M. Chen, Cognitive-behavioral therapy for irritable 
bowel syndrome: a meta-analysis., J. Psychosom. Res. 77 (2014) 1-12.

[54] A.C. Ford, N.J. Talley, P.S. Schoenfeld, E.M.M. Quigley, P. Moayyedi, Efficacy of antidepressants and psychological therapies in irritable bowel syndrome: systematic review and meta-analysis, Gut. 58 (2009) 367-378. doi:10.1136/gut.2008.163162.

[55] A.C. Ford, E.M.M. Quigley, B.E. Lacy, A.J. Lembo, Y.A. Saito, L.R. Schiller, E.E. Soffer, B.M.R. Spiegel, P. Moayyedi, Effect of Antidepressants and Psychological Therapies, Including Hypnotherapy, in Irritable Bowel Syndrome: Systematic Review and MetaAnalysis., Am. J. Gastroenterol. (2014). doi:10.1038/ajg.2014.148.

[56] H. Törnblom, D.A. Drossman, Centrally targeted pharmacotherapy for chronic abdominal pain., Neurogastroenterol. Motil. 27 (2015) 455-67.

[57] G.A. Fava, H.J. Freyberger, P. Bech, G. Christodoulou, T. Sensky, T. Theorell, T.N. Wise, Diagnostic criteria for use in psychosomatic research., Psychother. Psychosom. 63 (1995) $1-8$.

[58] L. Sirri, G.A. Fava, Diagnostic criteria for psychosomatic research and somatic symptom disorders., Int. Rev. Psychiatry. 25 (2013) 19-30.

[59] J.S. Labus, E.A. Mayer, L. Chang, R. Bolus, B.D. Naliboff, The Central Role of Gastrointestinal-Specific Anxiety in Irritable Bowel Syndrome: Further Validation of the Visceral Sensitivity Index, Psychosom. Med. $69 \quad$ (2007) 89-98. doi:10.1097/PSY.0b013e31802e2f24. 